\title{
Kein Selbstläufer
}

Liebe Leserin, lieber Leser,

langsam rückt die ATZlive-Konferenz „Automatisiertes Fahren“ näher; am 13. und 14. Oktober 2020 ist es soweit. 2020 ist eine Chance für kleinere Veranstaltungen: Große wie die SPS wurden nach langem Hin und Her abgesagt, die Electronica traf mittlerweile das gleiche Schicksal, und die CES 2021 hat schon länger den Status „keine persönliche Teilnahme zugelassen“. Wer spezialisiert und klein ist, hat die Chance, mit Präsenz an den Start gehen zu können. Und das ist gut so.

Die Teilnahme an Fachdiskussionen zum autonomen beziehungsweise automatisierten Fahren tut not, denn ohne diesen Austausch tritt das Thema auf der Stelle. Nach wie vor bin ich der Ansicht, dass die Aufgabe für einzelne OEMs zu groß ist und eigentlich an vielen Stellen sogar industrie- oder länderübergreifend angegangen werden müsste. Zwar tun sich nach der geplatzten Offensive von BMW und Daimler neue Partnerschaften auf, seien es Daimler plus Nvidia, BMW plus Intel/Mobileye oder Ford plus VW. Aber selbst das könnte nicht ganz reichen, weil der zu erklimmende Berg einfach wahnsinnig steil und sehr hoch ist. Bereits im Oktober 2019 berichtete Paul Hansen in seinem Report on Automotive Electronics - Teil der ATZelektronik seit Ausgabe 1-2/2020 - über die erheblichen Probleme bei der Erkennung von beispielsweise Fußgängern durch automatische Notbremssysteme (AEB), was eine der Voraussetzung für autonomes Fahren ist. Diese Problematik einer lückenhaften Hinderniserkennung geht auch aus einer Studie der American Automobile Association von August 2020 hervor. Es besteht also eindeutig großer Validierungs- und Verbesserungsbedarf, soll der Rechner jemals wirklich die komplette Verantwortung für das Fahrzeug tragen und der Mensch nicht mehr als Rückfallebene fungieren. Um die Aspekte wie AEB und vieles andere irgendwann perfekt $\mathrm{zu}$ lösen, brauchen wir aber Wissenstransfer. Auf der Konferenz „Automatisiertes Fahren“ werden deshalb eine Reihe hochkarätiger Redner mit Themen von der Evaluierung virtueller Fahrversuche bis hin zum Erhalt der Funktion von automatisierten Fahrfunktionen über die gesamte Fahrzeugnutzungsdauer auftreten: Damit betrachten wir auf der Veranstaltung die Entwicklung automatisierter Fahrfunktionen von der Wiege bis zur Bahre und bieten zudem die Gelegenheit für einen Austausch unter den Besuchern.

Die Umsetzung des automatisierten Fahrens, beziehungsweise der vielen kleinen Teilschritte dorthin, wird bei weitem nicht so trivial, wie sich das viele wünschen und alles andere als ein Selbstläufer. Und wer weiß, wie es am Ende mit der Realisierung steht unter wirtschaftlichen, sicherheitstechnischen oder auch ethischen Gesichtspunkten.

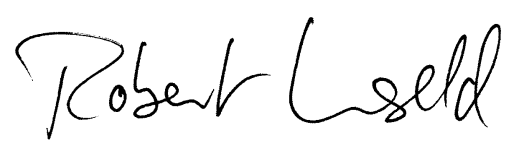

Robert Unseld

Verantwortlicher Redakteur

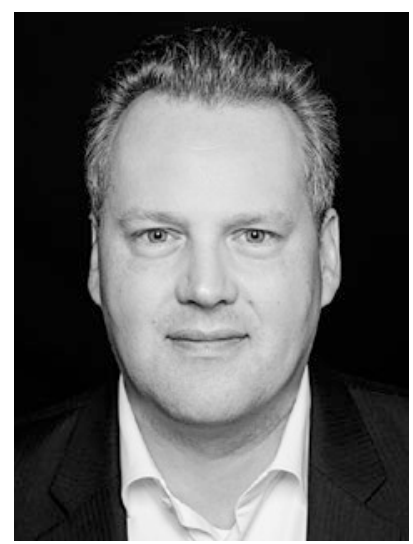

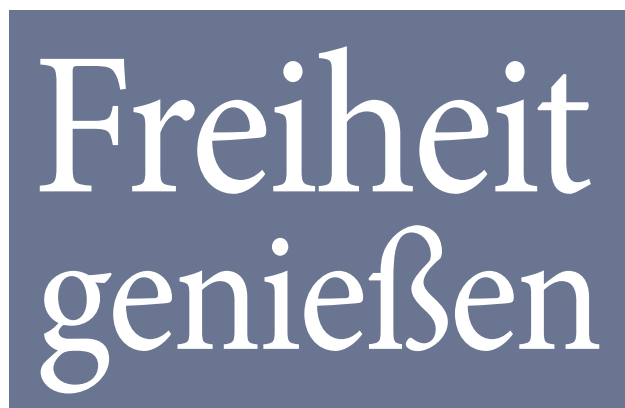

Und gleichzeitig sicher im regulierten Umfeld bewegen?

Funktionsumfänge steigen. Entwicklungszyklen verkürzen sich und lassen kaum Zeit zum Atmen.

Dieser Komplexität setzen wir methodische Ansätze für Entwicklung und Absicherung entgegen, die wir Hand in Hand mit Industrie und Wissenschaft entwickeln. Damit möchten wir Ihnen den Weg ebnen, leidenschaftliche Ideen in innovative Technologien zu verwandeln. Lassen Sie sich begeistern: technologisch und menschlich!

ITK Engineering GmbH - Ihr zuverlässiger Partner für System- und Softwareentwicklung.

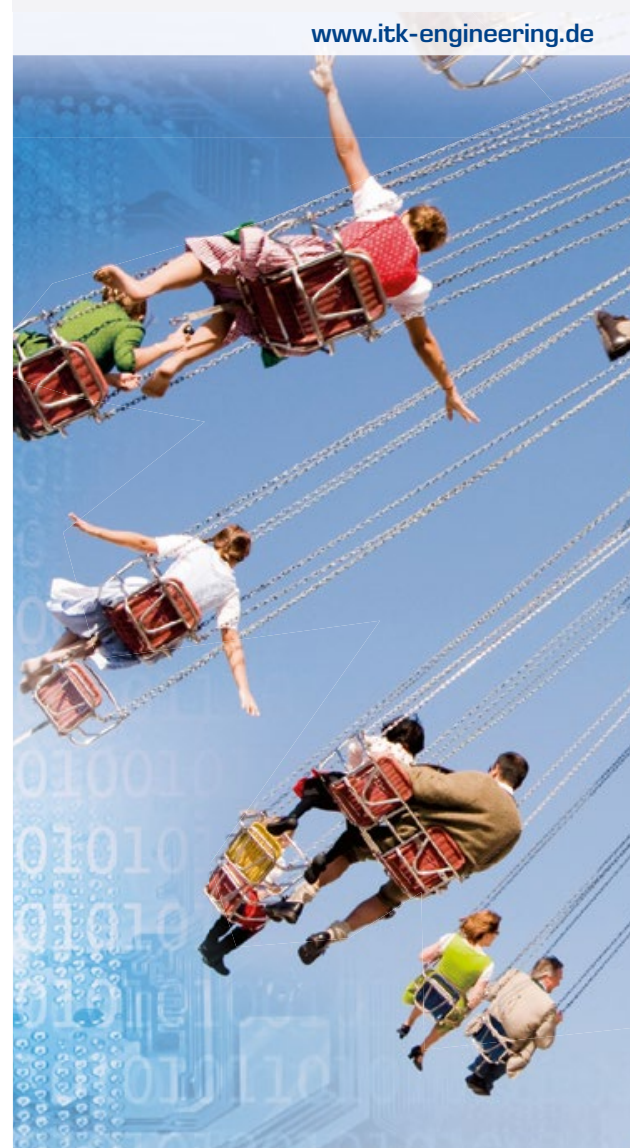

